\title{
El lado siniestro de la metáfora "nativos" versus "inmigrantes" digitales: El caso de unos profesores de escuela media de Misiones ${ }^{1}$
}

\author{
Laura Siri (Universidad de Buenos Aires) \\ Recibido: 23/1 1/09 \\ Aceptado: 15/12/09
}

RESUMEN: Se analizan las actitudes y creencias de unos docentes de escuela media acerca del uso de internet. Especialmente, cómo legitiman, o deslegitiman, su propia autoridad en función del "alfabetismo digital" atribuido a sus alumnos. La hipótesis es que, tras una preocupación manifiesta por las actividades online de los jóvenes, subyace otra referida a las propias supuestas limitaciones cognitivas y de acceso físico a las tecnologías de la información y la comunicación (TIC). Asimismo, se plantea que intentar explicar esta percepción en términos de nativos vs. inmigrantes digitales naturaliza una autodescalificación socialmente construida.

Palabras clave: Internet / alfabetismo digital / nativos digitales / inmigrantes digitales

The dark side of the digital "natives" vs. "inmigrants" metaphor: Middle school teachers in Misiones case

SUMMARY: Attitudes and believings from a group of intermediate school teachers regarding the uses of the Internet are analyzed within this paper. Focus is placed upon how those teachers legitimate or delegitimate their own authority, according to how much "digital literacy" they attribute to their pupils. The hypothesis is that, under a manifest concern regarding their online activities, lies another referred to their own perceived limitations, cognitive as well as related to the physical access to ICT. Moreover, it is argued that an eventual intent to explain these perceptions in terms of digital "natives" vs. "inmigrants" is only a way to naturalize a self disqualification socially constructed.

Keywords: Internet / digital literacy / digital natives / digital immigrants

1 Una versión diferente de este trabajo fue presentada como ponencia en el Primer Congreso Argentino de Estudios Sociales de la Ciencia y la Tecnología, realizado los días 5 y 6 de julio del 2007, en la Universidad Nacional de Quilmes (Argentina). 
El binarismo excluye el mundo imprevisible e infinito de las terceridades.

ANÍBAL FORD ${ }^{2}$

$\mathrm{H}$ ace ya varios años que Aníbal Ford me señaló - en comunicación personal- que internet hace cada vez más accesible una gran masa de información, y que este hecho va acompañado de una fuerte modificación en las relaciones de poder y saber entre, por ejemplo, los diarios y sus lectores, los médicos y sus pacientes, los jefes y los empleados. También, como interesa específicamente para este artículo, entre los profesores y sus alumnos. ${ }^{3}$

Con esta observación en mente, lo que sigue mostrará cómo unos docentes cuyo testimonio se recabó en este estudio manifiestan una percepción muy negativa acerca de su propia capacidad como educadores frente a alumnos que parecen moverse como peces en el agua en internet, así como diferentes maneras en que esta situación podría interpretarse o explicarse.

Porque, aunque las nuevas tecnologías acompañen este tipo de cambios y parezca que la brecha generacional es más grande que nunca, el rol del docente hoy también puede consi- derarse más importante que en otras épocas, a pesar de que ciertos discursos dominantes contribuyan a su descalificación y autodescalificación. Entre otras razones porque para poder lidiar con un exceso de información se necesita tener capacidad de contextualizarla, interpretarla, seleccionarla y ampliarla. Este tipo de tareas, a priori parecen más propias de quienes tienen mayor madurez y formación profesional para encararlas que de estudiantes adolescentes. Los supuestos "inmigrantes digitales" son, por lo tanto, tan necesarios como los supuestos "nativos" para la construcción social del conocimiento y un discurso que naturalice la devaluación de los saberes de los primeros necesita ser desarticulado, si se quiere lograr algo parecido a la llamada "inclusión digital".

\section{Marco teórico y algunos antecedentes}

Este análisis se inscribe en el marco de los estudios cualitativos sobre el consumo cultural, como los publicados por Roger Silverstone (1996). Además, se utiliza el concepto de capital sim-

2 “La tribu televisiva y el mercado de la soledad". Navegaciones (Ford 1994: 165).

3 Difícilmente este artículo hubiera podido existir sin haber pasado tantos años trabajando con Aníbal Ford, fallecido el 6 de noviembre del 2009. Siento la pena de haber perdido al maestro y al amigo, y la extrañeza de, por primera vez, estar publicando un trabajo tan inspirado en su pensamiento sin poder compartirlo con él. El comentario citado lo tengo escrito de su puño y letra en uno de los tantos papeles que escribía para ordenar las ideas, y probablemente es de 1994. 
bólico de Pierre Bourdieu (1998) y se extienden los conceptos de conocimiento tácito y codificado (Nonaka y Takeuchi 1995) a un entorno como la escuela, donde el aprendizaje no es un medio sino un fin.

Paralelamente, en el contexto discursivo actual, se insiste desde diversos medios e instituciones acerca de la necesidad de los docentes de incorporar las computadoras a su práctica laboral. Numerosas investigaciones académicas analizan cómo llevar a cabo este objetivo, pero pocas son las que estudien las actitudes subjetivas de los docentes hacia las herramientas informáticas.

Sin embargo, como dice la investigadora mexicana Guadalupe Becerra, las representaciones de los docentes acerca de las TIC no pueden dejar de influir en los eventuales usos educativos de las herramientas informáticas. La misma autora observa que

[...] en el desarrollo cotidiano del proceso educativo actual se ha generado una situación problemática respecto a la comunicación entre maestros y alumnos: éstos se han vuelto más competentes para el manejo de las tecnologías de comunicaciones y eso se traduce en procesos educativos deficientes de interacción, porque no están ambos en el mismo nivel de lenguaje (Becerra 2003).

Martín Barbero (2000) también analiza los procesos económicos, políticos y culturales que se fueron redefi- niendo con la aparición de las TIC en la educación:

Lo que la trama comunicativa de la revolución tecnológica introduce en nuestras sociedades no es tanto una cantidad inusitada de nuevas máquinas sino un nuevo modo de relación entre los procesos simbólicos -que constituyen lo cultural - y las formas de producción y distribución de los bienes y servicios.

El autor también destaca que el saber, fuente de poder desde la antigüedad hasta hoy, siempre fue centralizado y personificado en figuras sociales determinadas. La nueva era atentaría contra esa tradición. En particular, la escuela ha dejado de ser el único lugar de legitimación del saber, porque hay una multiplicidad de saberes que circulan por otros canales.

Asimismo, una investigación trianual encabezada por la estudiosa argentina Roxana Cabello (2006) propone recuperar las percepciones e intereses de los propios docentes con respecto a las TIC y concluye que, más allá de que los maestros participantes en su estudio reconozcan la importancia de incorporar la informática a la enseñanza, también se sienten distantes de este tipo de tecnologías y visualizan la escuela como parte de un mundo movido por una lógica diferente de la que ellos proponen.

En otras palabras - tomadas de Bourdieu (1997) y de Bourdieu y Pas- 
seron (1998) - , puede decirse que las TIC son un factor que participa de la actual transformación del campo formado por el sistema de relaciones sociales dentro del ámbito educativo. Esto es porque el capital simbólico asociado a este, el saber, ya no está en posesión exclusiva de los docentes. Entonces, deben cambiar las reglas o principios que hacen funcionar dicho campo, así como la capacidad de los distintos actores de aplicar nuevas reglas.

En otro orden de cosas, para este estudio no interesa mucho si verdaderamente existe o no una nueva era de la comunicación, si se trata en realidad de una sobrevaloración de las tecnologías informáticas, o si en efecto hay una auténtica ruptura con los modos de relacionarse en el pasado dentro del campo educativo. El foco está puesto en la percepción que tienen ciertos actores - los docentes- dentro de dicho campo, de que así ocurre, aunque esa percepción esté modelada en parte por un discurso acrítico acerca de la tecnología que la asocia con el futuro, el éxito, la superioridad y la competitividad. Porque esa percepción es lo que en definitiva modifica el sistema subjetivo de expectativas y predisposiciones adquirido a través de las experiencias previas de los sujetos involucrados (es decir, lo que Bourdieu llama "habitus").

Lo importante, entonces, es si los docentes perciben que están perdiendo capital simbólico y que los alum- nos lo están ganando. Asimismo, hay que considerar qué actitudes de resistencia, aceptación o indiferencia adoptan ante esa situación percibida. Como resume Becerra (2003):

La forma como operan las representaciones sociales de los maestros en relación con el uso de la computadora en la docencia muestra el conocimiento compartido acerca de lo que ellos, como usuarios de la tecnología, esperan respecto a su propia identidad de docentes, la función educativa y pedagógica que desempeñan y su posición laboral como usuarios de la tecnología, aspectos que son analizados desde las prácticas y las actitudes.

Cuando se habla de percepciones se lo hace de un modo similar a la noción de representaciones sociales de Moscovici (1986), quien las explica como conjuntos más o menos estructurados o imprecisos de nociones $y$ creencias que permiten a los sujetos percibir, valorar, comunicarse y actuar, y, así, orientarse en el contexto social donde viven, racionalizar sus acciones, explicar los eventos relevantes y defender su identidad.

Esta definición puede utilizarse en combinación con el concepto de "economía moral", desarrollado por Silverstone (1996), en referencia al modo particular en que cada grupo se apropia de los productos y significados de la economía formal, basada en las mercancías y los individuos, según sus propios valores e intereses. Como 
dice el autor, se trata de una economía de significados y a la vez significativa. $Y$ es moral porque implica actividades definidas e informadas por un conjunto de cogniciones, evaluaciones $\mathrm{y}$ estéticas, definidas e informadas a su vez por las historias, las biografías y las políticas del grupo y de sus miembros. En particular, en el capítulo noveno de dicha obra compilada por Silverstone: "La contextualización del ordenador doméstico, recursos y prácticas", de Graham Murdock, Paul Hartman y Peggy Gray, se analizan las distintas representaciones y discursos en las familias sobre cuál es el uso "adecuado" de la computadora y cómo el resultado de estos forcejeos depende de la estructura de autoridad y la distribución de conocimientos técnicos en cada familia. Es decir, de sus "economías morales". Un análisis análogo se podría realizar acerca de la economía moral, ya no de la familia, sino de la escuela.

Por cierto, hoy en los estudios de comunicación mediada por computadoras es muy habitual tratar de explicar la supuesta mayor familiaridad de los jóvenes con respecto a los adultos en el hecho de que los primeros serían "nativos" del ciberespacio mientras que los segundos solo "inmigrantes".

La metáfora Digital Natives fue lanzada por Marc Prensky para referirse a quienes nacieron con estas tecnologías incorporadas a su vida, en oposición a los Digital Immigrants, quienes llegaron a las TIC siendo ya adultos, en un ensayo publicado el 2001. Pero como se argumentará más adelante, esta metáfora implica una naturalización de relaciones supuestamente asimétricas, que de ningún modo puede ser aceptable sin al menos cierta crítica.

Finalmente, el presente estudio también puede encuadrarse en la teoría acerca de los conocimientos "explícitos" o "codificados" versus los "tácitos".

Según Nonaka y Takeuchi (1995), el "codificado", o conocimiento explícito, es objetivo y racional, y puede ser expresado con palabras, números, series de instrucciones o fórmulas. El tácito, por su parte, es aquel que una persona, comunidad, organización o país tiene incorporado en su cultura y es difícil de explicar y de transmitir: es el campo de la "inteligencia práctica".

El conocimiento explícito, como es acumulado centralmente (en bibliotecas, medios magnéticos y grupos de personas/docentes), puede ser apropiado en forma organizada. En cambio, el conocimiento tácito está en diversas personas que tienen enfoques diferentes y, por lo tanto, funciona en forma descentralizada.

La creación de conocimiento en una organización se produce a través de intercambios constantes entre conocimientos tácitos y explícitos, en lo que se llama la "espiral del conocimiento". 


\section{Metodología}

Los elementos metodológicos que guiaron este análisis de la actitud hacia las TIC de los docentes de escuela media involucraron, en primer lugar, un taller de discusión sobre esta temática destinado a este tipo de profesores. Al final de dicho taller se les pidió a los 46 asistentes plasmar por escrito una o más situaciones surgidas en su ámbito laboral que les hubiesen generado preguntas, inquietudes o preocupaciones en relación con la "vida digital" de sus alumnos. Por último, sobre la base de los recursos teóricos descritos, se analizó dicha producción textual para caracterizar las representaciones objeto de esta investigación.

Ese taller constituyó un espacio de reflexión y diálogo acerca de diversas cuestiones: cambios en las relaciones de saber y de poder entre profesores y alumnos; análisis de diversos fenómenos ciberculturales; los cibers como lugares que preocupan a los docentes aunque posibilitan a muchos el acceso a internet; el rol del docente como mediador entre el estudiante y las nuevas tecnologías; y desafíos de la hiperinformación.

Esta actividad se llevó a cabo en la semana del 30 de mayo al 2 de junio del 2005 en la ciudad de Posadas, en Misiones, como parte de una capacitación docente para profesores y directivos de EGB3 y Polimodal de esa provincia. Los asistentes eran representantes de las escuelas de toda Misiones y profesores de variadas disciplinas de la escuela media. Este tipo de capacitaciones es organizado en todo el país por el área de Desarrollo Profesional Docente, de la Dirección General de Gestión Curricular y Formación Docente, dependiente del Ministerio de Educación, Ciencia y Tecnología de la Nación, en combinación con los respectivos ministerios provinciales. ${ }^{4}$

La interpretación de los discursos escritos generados en el marco de dicho taller tiene su eje metodológico en el análisis propuesto por Jensen y Jankowski (1993), quienes sostienen que las actitudes, representaciones y creencias no son observables empíricamente, sino que se interpretan partiendo de lo que se dice y poniéndolo en contexto. Finalmente, desde esta perspectiva metodológica, el discurso se considera un sistema de significación donde lo expresado no solo supone significados individuales, sino que da cuenta de un sistema de relaciones sociales y conocimientos culturales.

4 Dado que dicha actividad no fue organizada como un focus group destinado a generar investigaciones, sino como una capacitación para docentes, en esta publicación se tiene especial cuidado en no dar información que pueda identificar individualmente a los participantes. 
Las limitaciones de este estudio impidieron realizar otros análisis que, no obstante, serían útiles en futuras investigaciones sobre la misma temática. Por ejemplo, mediante una metodología cuantitativa, se podrían estudiar a través de un reconocimiento numérico las actitudes de los profesores frente a la informática. También se podrían utilizar metodologías cualitativas de carácter interpretativo estructural, con grupos de discusión integrados por profesores seleccionados de la muestra cuantitativa, para explorar formas compartidas con las que se comprende el hecho social analizado. Estos métodos, asimismo, funcionarían como herramientas de triangulación de resultados obtenidos. Por otra parte, también sería interesante la realización de un estudio similar, pero enfocado en las actitudes hacia las TIC del otro grupo de actores que forman el campo educativo: los estudiantes. Por todo ello, este trabajo - nacido de una oportunidad única de haber podido reunir en un mismo lugar una variada muestra de docentes de escuela media de toda la provincia de Misiones- es solo una primera aproximación a un problema que podría estudiarse a escala nacional y con recursos de investigación y objetivos más abarcativos.

\section{Los peligros del cibercafé}

Una de las manifestaciones más generalizadas entre los participantes del mencionado taller es el reconocimiento de que los cibercafés, telecentros y locutorios públicos facilitan mucho a sus alumnos el acceso a internet, en especial a aquellos que no tienen computadora en su casa. No obstante, son lugares percibidos con mucha aprehensión. Por ejemplo, una docente expresó que:

En cierto modo preocupa el hecho de que la gran mayoría de los chicos se pasan horas y horas frente a una computadora, ya sea para rescatar cosas buenas como así también cosas malas. Como docentes deberíamos aprender a usar [la computadora] en primer lugar nosotros, para enseñar a usar a nuestros alumnos y ayudarlos a seleccionar información que pueda ser de utilidad para ellos. Pero no se descarta que por iniciativa propia si desean buscar cosas malas lo harían de cualquier modo. ${ }^{5}$

Aquí se pueden señalar varias cosas. Por un lado, la preocupación acerca del uso que dan a su tiempo los jóvenes. Luego, se ve una actitud bastante maniquea: en la red hay cosas "buenas", pero también "malas". No queda claro cuáles son, pero se admi-

5 Como los testimonios fueron brindados por escrito, se respeta en la transcripción los errores gramaticales, ortográficos o sintácticos que pudieran presentar, con el fin de alterarlos lo menos posible. 
te que los docentes deberían internarse más en el mundo poco conocido de las TIC, para ayudar a los jóvenes a sortear las cosas "malas". Finalmente, se concluye en una derrota: hagamos lo que hagamos, ellos encontrarán lo "malo" sin que se pueda evitar. A continuación, la misma docente plantea su concepto de "economía moral":

Deberíamos hacer lo posible para adaptarnos a este nuevo medio y hasta de darle el uso adecuado conforme a los criterios personales. Como docentes, si deseamos incorporar este medio como una herramienta didáctica en la clase, deberíamos tener en claro qué cosas deseamos que el chico busque, marcándoles pautas bien precisas sobre las cuales se basará, de modo que no se extienda tanto en la búsqueda de información tan variada que ni siquiera lee.

La idea es controlar los tiempos de permanencia frente a la computadora, marcar con precisión qué se puede hacer con ella y qué no. Pero reconoce que, aunque crea en la necesidad de estas normativas, "[...] es importante insertarse más y tratar de convivir más con este medio, ya que de lo contrario quedaría perdida en el tiempo y desconectada del mundo". O sea que, en el fondo, aquel ámbito desconocido lleno de cosas "malas" es percibido como equivalente al "mundo", del cual no se puede desconectar.

Con respecto a los cibercafés, lo que más asusta es la percepción de que en esos lugares los adolescentes están libres del control adulto, el que es considerado necesario.

Los cibercafés son espacios que me preocupan permanentemente por tratarse de un espacio donde "el control" no existe, los jóvenes tanto como los adultos acceden a páginas que muchas veces en lugar de enriquecerlos, tergiversan todo tipo de conocimiento,

comenta un docente. A pesar de ello, dice resignado: "El ser humano debe adaptarse a los cambios, todo evoluciona y no podemos frenar la situación". Y recomienda acciones sugestivas:

El joven adolescente necesita de una "mano firme" que le marque un contexto positivo donde él pueda aprender con gusto todo tipo de disciplinas y pueda valorar ese instrumento que significa un potencial cuando es usado adecuadamente.

De nuevo, el uso "adecuado" frente al "inadecuado", pero con el agregado de que, para obligar al adolescente a distinguirlos, la mano debe ser "firme".

Otros manifiestan con más suavidad ideas parecidas. Como dice una profesora:

Los cibercafés nos preocupan en el sentido de que, como cualquier lugar público, al cual concurren nuestros alumnos, ellos se manejan sin un con- 
trol en esos lugares específicos. Pero a su vez el cibercafé es una fuente de información más, como lo es una biblioteca, entonces se necesitaría contención por parte de los padres, profesores, para guiar a los adolescentes a discernir tanta información encontrada en estos lugares.

\section{El uso "adecuado" de la PC}

Comenta una docente:

Me acuerdo que una vez los chicos de $9^{\circ}$ año, que hacen una revistita escolar con la profesora de lengua, extrajeron una información sobre el número 11, en la cual se hacía referencia a que las torres gemelas se parecen al número 11, que [el atentado] ocurrió un 11 de septiembre y otras cosas más que ahora no recuerdo, pero me llamó la atención porque ellos leyeron una parte de esa información y luego me la mostraron para que yo también opinara sobre eso. De hecho lo leí y me sorprendí de que ellos algunas veces sí prestan atención a algo.

Este testimonio denota que, por un lado, la profesora asume que los alumnos normalmente no se interesan por nada, no se hace ilusiones al respecto y manifiesta asombro ante la excepción. Por otro lado, es evidente que esos alumnos la hicieron partícipe de su descubrimiento y consultaron su opinión. Los estudiantes estaban ubicando con naturalidad a la docente en un rol contextualizador y orientador acerca de la información.

Otros profesores ya empiezan a darse cuenta de la necesidad de cambiar su rol tradicional:

Considero que el rol docente es el de enseñar a distinguir la información más verosímil, debería triangular la recibida para poder tomarla como "verdadera", además ser crítico en el análisis de lo encontrado, puesto que no todo lo que figura en la red es bueno.

Si bien en este caso se plantea un rol de orientación y mediación, todavía se hace con el objetivo de distinguir lo "verdadero" de lo "falso" y lo "malo" de lo "bueno". Otro docente dijo: "Es un tema muy preocupante porque la mayoría de nuestros jóvenes están solos y pasan mucho el mayor tiempo mirando «basuras»". $Y$ uno más: "Me preocupa el «abuso» que se le da a la Internet, entendido por uso indebido de la misma". Este tipo de expresiones con carga axiológica negativa se repitió con gran frecuencia en los discursos de los docentes participantes del taller. ${ }^{6}$

Algunos lo tienen claro: lo "malo" es identificable bastante linealmente con lo "lúdico". Así lo muestra este ejemplo:

6 En todos los casos, las palabras entrecomilladas fueron puestas de ese modo por ellos. 
Una situación que me ha generado preocupación es la cantidad de horas de juego de algunos de mis alumnos. Es como si fueran adictos, han cambiado en su forma de relacionarse, de contestar, de trabajar, etc. En su lista de prioridades primero está el juego. He pensado mucho en qué hacer, ya he hablado con ellos pero no ha dado resultado. Pienso hablar con los padres, pero es una situación muy tirante meterse en la familia... Lo sigo pensando.

Es decir que hay una percepción de que usar la computadora para jugar no está del todo bien. Este dato es similar al obtenido en el estudio de Silverstone (1996) hace más de veinte años en Inglaterra, que mostró el conflicto en las familias británicas acerca de las distintas representaciones y discursos en torno a cuál era el uso "adecuado" de la computadora, concretamente los usos "didácticos" versus la apropiación de dichos equipos como máquinas de juegos.

Otros profesores apelan directamente a las prohibiciones:

Como docente era muy reacio a la utilización de la informática y en varias ocasiones traté de evitar el uso de esta herramienta, en parte por desconocimiento y por temor a sentirme sobrepasado por los chicos y también para evitar que los alumnos simplemente bajen información sin previa lectura y análisis. Eso se manifestaba por ejemplo en nunca permitir presentación de trabajos prácticos hechos en computadora, pensaba que así evitaba copias o facilitaba investigar y buscar información.

El testimonio habla en tiempo pasado, pero no aclara si en el presente o en el futuro piensa cambiar de estrategia. Y refleja claramente el miedo a la pérdida de autoridad frente a los alumnos si ellos utilizan las herramientas informáticas, a cuyo uso el docente dice ser reacio.

Con respecto al tema de las copias, mencionadas por este y casi todos los testimonios, es sugestivo que en algunos casos los propios docentes confiesen incurrir en las mismas actitudes que reprochan en sus alumnos. Como cuenta un participante:

Una vez para un trabajo de Psicología Social, nos pasó que para poder terminarlo a tiempo bajamos mucha de la información que estaba en Internet. Lo que no hicimos fue una buena selección de la información, una lectura e interpretación de la misma, pero tampoco una conclusión del trabajo para constatar que dicha información daba a entender que los supuestos que teníamos eran verdaderos. Conclusión, yo personalmente le pedí disculpas a la profe, rehice el trabajo y di un buen final para demostrar que el trabajo de investigación sirvió como experiencia para la materia pero también para aprender a tomarme el tiempo y tener más cultura cibernética. 


\section{Estrategias ante lo inevitable}

La impresión que dejan estos testimonios es que, por un lado, los docentes consideran no tener el alfabetismo digital que - a regañadientes o nocreen imprescindible para sobrevivir ante los nuevos retos de su profesión. Por otro lado, perciben en sus alumnos habilidades tecnológicas superiores a las suyas y sienten que esa actividad debería controlarse de algún modo, pero no saben bien cómo. Algunos utilizarán la "mano firme". Otros apelarán a recursos más amables, como en este caso:

Los cambios en las relaciones de saber $y$ de poder entre el que enseña y el que aprende son notables y creo que sirven para incorporar a nuestras relaciones un poco de valores casi olvidados, como la humildad de reconocer sin vergüenza que el alumno sabe o tiene mejor información que yo; y el respeto de dejar de ver a los otros (alumnos o hijos) como que no saben nada y que sólo yo tengo razón. Aprender a escuchar y enseñar a analizar. Y la cooperación: es muy lindo en una clase tener la oportunidad de brindar el conocimiento de manera compartida (un ida y vuelta) donde los alumnos escuchen, junto con el profesor, los comentarios de alguno de sus propios compañeros.

Un participante hasta llegó a atribuir a los mismos docentes la culpa de la ajenidad que percibe en ellos con respecto al uso de internet: "Hoy en día la tecnología te hace hombre y la no tecnología pareciera ser que te hace mono. Pero la verdad es que nosotros mismos nos volvemos monos, y culpamos a la tecnología". En otras palabras, el que no puede subirse a la cresta de la ola es prácticamente un animal, y además es su culpa.

Otra estrategia ante la percepción de la superioridad técnica en los alumnos es afirmar el valor de otras capacidades que sí creen poseer. Como reflexiona un profesor,

[...] el alumno maneja mucha más información que el docente, ya que ellos se pasan mucho tiempo en un ciber mientras que el docente trabaja. Esto no quiere decir que el alumno ahora sepa más que el docente ya que ellos tienen problemas en la comprensión de lo que leen.

Este testimonio intenta distinguir valorativamente la información del conocimiento. Los alumnos tendrían información, los docentes, conocimiento. Además, los alumnos "pasan el tiempo" en el 'ciber'. El docente, en cambio, "trabaja". Por último, se da por sentado que los alumnos no comprenden lo que consiguen en internet.

Y más allá de si la estrategia elegida implica aceptación, rechazo o negociación con las TIC, la percepción es que "algo" pasa con ellas y, guste o no, "algo" hay que hacer: "Creo que los docentes que somos reacios a la 
computadora de alguna manera $u$ otra tendremos que acercarnos para poder por lo menos compartir situaciones de alumnos que sí viven con la tecnología", estima otro participante.

\section{Conocimientos codificados vs. conocimientos tácitos}

La referencia a la pérdida de valor - en términos de capital simbólicode sus conocimientos calificables como "codificados", también es un denominador común en los participantes. Una docente, muy clara al respecto, dice por ejemplo que

[...] antes era más fácil enseñar, cuando la única información que manejábamos era la que se veía por TV o se escuchaba por radio. Los alumnos vienen hoy con ciertos planteos [a los] que no encontramos la respuesta en un libro de texto.

Mientras tanto, como relata este otro testimonio, los alumnos exhiben ampliamente sus conocimientos incorporados en forma tácita:

Sucede muy frecuentemente que, al incorporar la tecnología como recurso didáctico (uso de proyectores multimedia, power point, etc.), sean los alumnos quienes tengan que asesorar, colaborar, ayudar "enseñar"! a los profesores $(-)$. Me ha pasado muchas veces. ${ }^{7}$
A la inversa, como dice el siguiente discurso, los docentes tienen problemas para que los alumnos transformen en conocimiento tácito individual interiorizado el conocimiento codificado obtenido vía internet:

Trabajando con $8^{\circ}$ año EGB3 de Ciencias Naturales, concretamente física química, les digo a los chicos que para la próxima clase me traigan toda la información que consigan sobre el átomo. Los chicos cumplieron con $\mathrm{mi}$ pedido y en la siguiente clase un grupo de alumnos me presenta 60 hojas referidas al átomo, bajadas de Internet. Por supuesto, ellos cumplieron, pero qué pasó, yo no les expliqué qué información quería sobre el átomo concretamente, por lo tanto ellos fueron a Internet, escribieron la palabra "átomo" y luego imprimieron todo (... conflicto en la casa por el dinero gastado) pero nunca lo pudieron leer, es imposible. Esto me sirvió como experiencia para trabajos futuros. No se les puede pedir a los alumnos del EGB3 un tema y que ellos lo encuentren, porque en Internet van a conseguir mucha información que no sabrán clasificar.

Este ejemplo muestra, por otra parte, que aunque los docentes manifiestan preocupación ante el acceso a la hiperinformación por parte de sus alumnos y se sienten en inferioridad de condiciones frente a estos, en reali-

7 El signo de admiración y el emoticon corresponden al original. 
dad los jóvenes tampoco saben qué hacer con esa hiperinformación. Cuando estos presentan un trabajo de sesenta páginas descontextualizadas, ¿no se podría pensar que le están pidiendo a su docente que cumpla un rol de facilitador o mediador, y no que sepa de memoria lo que dicen esas páginas ni que domine como un experto la tecnología para hallarlas?

Sin embargo, se trata de un rol en el que a los docentes participantes de este estudio, en general, no parecen sentirse cómodos:

Debemos comprender que ya no somos los únicos que "poseemos el saber". Eso nos coloca en una situación desconocida y a veces desesperante para quienes estamos acostumbrados a ser "libro de consulta". También nos coloca en una posición de igualdad con el resto de las personas, e inseguridad en muchos casos. Por ejemplo, era común escuchar respuesta a cualquier pregunta de los alumnos, muy difícilmente escucharíamos de un docente responder que no sabe sobre algún tema. Ahora debemos sincerarnos con los alumnos y responder que no sabemos todo todo,

se queja un profesor. Otra dice:

En mi grupo de alumnos de primero polimodal suelen preguntar cosas de otros países, que no salen en el diario, noticias locales o nacionales, o de lugares y acontecimientos en el Brasil (soy profesora de portugués). Muchas veces no les sé contestar, aclarar dudas, porque no fui a esos lugares ni estoy todo el día conectada a Internet, como para saber todo. En cambio ellos sí, se la pasan chateando, entrando en páginas. Entonces es como que ellos saben más que la profesora.

En general, los participantes notan que los alumnos saben cosas que no les fueron impartidas en clase. Pero ninguno señala la importancia de que los alumnos elijan a su docente para comentarlas. Ninguno manifestó haber pensado que, con ese tipo de preguntas, los alumnos quizá no les están "tomando examen" para ver si saben "todo". Quizás solo estén pidiendo contextualización, interpretación, selección y ampliación de una información que, por sí mismos, no están en condiciones de alcanzar, más allá del alfabetismo digital que posean.

Ante esta falta de confianza en la utilidad de sus propios saberes y habilidades, la percepción de los profesores es que lo aprendido por los alumnos online puede incluso ser más valioso que lo enseñado en clase. Como ilustra este ejemplo:

Los docentes ya no se diferencian como antes de los estudiantes por ser "los que saben", ya que en muchos casos aprenden [online] en una hora o a veces en menos tiempo, porque les parece más dinámico que presenciar una clase muchas veces de 5 horas donde salen sin ningún conocimiento nuevo". 
Se puede interpretar a grandes rasgos que los alumnos tienen dificultades para transformar el conocimiento codificado, profusamente obtenido vía internet, en conocimiento tácito individual interiorizado. Los docentes, a su vez, tienen problemas para adaptar sus prácticas pedagógicas a las posibilidades y desafíos que plantean las nuevas tecnologías.

Por otra parte, los conocimientos tácitos de los alumnos acerca del manejo en sí de la tecnología llegan a ser percibidos por los profesores como de mayor capital simbólico que los "codificados" impartidos desde sus respectivas disciplinas.

\section{Un contexto de pobreza}

Entre los docentes que asistieron al taller había algunos provenientes de las zonas más urbanas, como Posadas, donde el acceso a las TIC es relativamente accesible, y otros que, según refirieron en conversaciones personales, trabajan en instituciones donde a veces no hay siquiera electricidad. En estas últimas, cuenta una profesora,

[...] los alumnos son muy humildes, prácticamente no tienen acceso a Internet en un ciber porque, en lugar de gastar un peso, deben comprar pan o guardar para sus pasajes. Es por ello que aquí no existe la hiperinformación.

También hay localidades intermedias donde es raro tener internet en las casas, pero existe por lo menos un 'ciber'. En estas lo notable es que el 'ciber' puede ser una de las pocas fuentes de acceso a la información:

Hay lugares donde la presencia de bibliotecas o de diarios locales no existe o son pocos, mientras que los cibers están a la vuelta de la esquina y en número mayor, desde donde se puede acceder a información seguramente de mejor calidad.

Otro docente dijo en su testimonio:

En los pueblos pequeños nadie tiene acceso a Internet domiciliario y solamente hay 2 locales de cibercafés con 4 máquinas cada uno a un costo de 3,50 la hora. Pero sin embargo todos los alumnos tienen correo electrónico, aunque no sepan nada de informática, de manera que la pobreza ya no es un obstáculo de acceso a Internet.

Si la pobreza ya no es un obstáculo para acceder a la red es algo que habría que demostrar. Lo indudable es que en las ciudades más grandes del país, como Buenos Aires, el costo por hora de ir a un 'ciber' es bastante menor que en Misiones y, por otra parte, hay muchos.

Para acceder a internet en esa provincia, cuya población, además, tiene mucho menor poder adquisitivo que el de la Capital Federal, hay que pagar más. Así, menos familias tienen conectividad en el hogar y los lugares donde ofrecen el servicio son más escasos. 
Por otra parte, Misiones se caracteriza por la abundancia de escuelas rurales y zonas de extrema pobreza. Como explica un profesor: "[...] son profundas las asimetrías que existen entre los jóvenes de la ciudad y los de las zonas rurales, donde no hay posibilidades de que llegue Internet, los profesores tienen muchas escuelas, deben circular por cinco o seis establecimientos y el tiempo es un tirano". Es interesante que, aunque es sabido que en Misiones hay muchos docentes que viven por debajo o cerca de la línea de pobreza, ninguno utilizó esta línea de argumentación para explicar el escaso alfabetismo digital que dicen tener. Más bien, de sus testimonios se desprende que lo consideran una especie de estigma personal. Parafraseando a Prensky, su presunto problema sería no ser "nativos digitales".

\section{$\dot{2}$ "Nativos" vs. "inmigrantes" digitales?}

Como ya se mencionó, la tesis de Prensky es que nuevas generaciones de personas han incorporado infotecnologías prácticamente desde que nacieron y, por lo tanto, sus capacidades cerebrales probablemente tienen diferencias profundas con los demás. El límite temporal es bastante claro: los nacidos antes de la década de 1990 son todos inmigrantes digitales. No importa si se trata de Vinton Cerf, uno de los padres de internet; Tim Berners-Lee, el creador de la web;
Richard Stallman, el gurú del software libre; o Linus Torvalds, el desarrollador del kernel del sistema operativo GNU Linux. Por su edad, son todos inmigrantes digitales. Por lo cual se presupone que, hagan lo que hagan, jamás podrán superar en competencias tecnológicas a los jóvenes nacidos con las tecnologías incorporadas.

El ensayo de Prensky alcanzó una popularidad tan grande que la expresión "nativos digitales" ya entró en el lenguaje de muchos como una categoría completamente naturalizada.

Sin embargo, como dice el economista, periodista y profesor Pablo Maas en su blog Economedia (2009) un problema importante de los trabajos de quienes apoyan la división entre inmigrantes y nativos digitales es su base empírica, muchas veces inexistente, poco representativa, sesgada o inaccesible al escrutinio académico.

Maas cita numerosos estudios que cuestionan esta metáfora. Por ejemplo, uno de Sue Bennett, Karl Maton y Lisa Kervin (2008), tres investigadores australianos, donde se argumenta que los usos y las habilidades tecnológicas de los jóvenes evidentemente no son uniformes, ya que los hay muy expertos y los hay bastante alejados de la tecnología. Por otra parte, menciona un paper de los británicos Anoush Margaryan y Allison Littlejohn (2008), donde se muestra que aun los estudiantes más idóneos en infotecnologías saben tanto (o tan poco) como sus profesores. 
Se podrían añadir muchos argumentos para objetar por estereotipada y falaz la visión de Prensky. Para empezar, solo puede ser catalogada como metáfora binarista, porque dividir la humanidad en solo dos categorías estancas es, como mínimo, muy reduccionista. Recuerda el clásico partido de fútbol donde juegan Estados Unidos versus "Resto del mundo", que da título a uno de los últimos libros de Aníbal Ford y su equipo (2005: 15), donde precisamente se cuestiona este tipo de clasificaciones. Generaliza impunemente tanto por el extremo superior como por el inferior, ya que ni todos los jóvenes son tan tecnologizados ni todos los mayores imprimen el correo electrónico para leerlo mejor o no pueden manejar un aparato sin estudiar el manual. La generalización es más preocupante si se tienen en cuenta las graves diferencias de acceso que existen para los jóvenes como para los adultos, debidas a desigualdades geográficas, sociales, económicas y culturales. Pensar que los jóvenes varones blancos de algunos estados o ciudades de Estados Unidos marcan una tendencia que todo el globo eventualmente ha de seguir es tan falaz como los mitos de la globalización analizados por Ferguson (1992).

La metáfora de Prensky, por otra parte, no deja de tener un lado aún más siniestro. Porque la diferenciación entre "nativos" e "inmigrantes" alude originalmente a desigualdad de derechos y oportunidades, marginación, discriminación, como las que se ven hoy día en los países centrales contra quienes se acercan a sus territorios (muchas veces desde ex colonias suyas) en busca de una vida mejor. Pensar que el uso de ciertas tecnologías delimita una especie de país, con nativos e inmigrantes, es implícitamente definir quiénes tienen derecho a qué capital simbólico en dicho "país".

Y como muchos estudios que simpatizan con el concepto de Prensky teorizan acerca de qué pasará cuando esas nuevas generaciones sean dueñas del poder y el dinero, puede deducirse que la clasificación del autor norteamericano también implica naturalizar cómo ha de producirse el reparto del capital material.

Suponer que hablar de "inmigrantes digitales" implica descalificación no es meramente especulativo. Está implícito en el ensayo de Prensky en frases tales como "Aquellos de nosotros que somos inmigrantes digitales podemos, y debemos, reírnos de nosotros mismos y de nuestro 'acento'". 8 Quiere decir, literalmente, que aquellos a quien llama "inmigrantes" digitales son ridículos. El hecho de que él

8 "Those of us who are Digital Immigrants can, and should, laugh at ourselves and our «accent»" (Prensky 2001: 2). 
mismo se incluya en la categoría no la vuelve menos descalificante.

Paralelamente, cuando se trata de habilidades lingüísticas, está claro en el lenguaje usual que tener un manejo "nativo" de estas es una ventaja difícil de superar. El uso cotidiano está lleno de frases como "habla inglés como un nativo", para referirse a la culminación del manejo de una lengua aprendida. Expresiones como "haber nacido a caballo" o "jugar al fútbol desde la cuna" también hacen referencia a una situación ventajosa derivada de un aprendizaje temprano. De hecho, las recomendaciones de Prensky en su artículo van encaminadas a que los "inmigrantes" aprendan a comunicarse en términos comprensibles por los "nativos", como forma de minimizar sus limitaciones. Después de todo, son los primeros quienes están supuestamente "en falta". Ni se le ocurre pensar que, dado que esos "nativos" tienen la curiosa propiedad de haber llegado después que los "inmigrantes" al "país", sería razonable pretender también que ellos aprendan a hablar el "antiguo" lenguaje, y no al revés.

En una reproducción del viejo binarismo entre "civilización" y "barba-

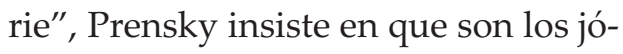
venes los únicos "hablantes nativos" del lenguaje digital de las computado- ras, los videojuegos y la internet. Pero, ¿quién tiene más fluidez en el conocimiento de los videojuegos, un adulto que trabaja en programarlos, o un joven que los juega? Dicho de otro modo, ¿quién sabe más de una tecnología, el que la produce o el que la consume? Prensky, aunque en otro ensayo (2004), menciona algunas tareas tecnológicas como la programación, pero en realidad casi todo lo que usa para ejemplificar son actividades de consumo. ¿Todos los jóvenes que usan Facebook sabrían programar un sistema como Facebook? ¿Alguien capaz para esta tarea pero nacido antes de 1990 ha de identificarse necesariamente con el lado "inmigrante" del país digital? Por otra parte, ¿qué es exactamente el "lenguaje de las computadoras y de internet"? Porque, por ejemplo, quien se habitúa mucho al mundo Windows típicamente nunca osa incursionar en el del software libre, y la mayoría de estos jóvenes "nativos" usan herramientas privativas, al igual que los adultos. ¿Da lo mismo si se usan entornos que respetan la libertad del usuario y que genuinamente están orientados a compartir, que sistemas donde la solidaridad entre usuarios está expresamente prohibida? ${ }^{9}$ ¿De qué sirve esa supuesta fluidez en el presuntamente existente lenguaje digital, sea este lo que

9 Para más información acerca de la importancia del software libre para la inclusión digital véase, por ejemplo, Siri, L. (2009). “La brecha digital, o cómo poner el carro delante del caballo" [en línea]. 
sea, si uno igual tiene la mente colonizada por un puñado de empresas que, por cierto, auspician siempre que pueden la clasificación propuesta por Prensky?

Se puede postular, por lo tanto, que la razón de que docentes como los mencionados en este trabajo se sientan inferiores a sus alumnos porque no usan tan bien como ellos las infotecnologías no es que los primeros sean "inmigrantes" y los segundos "nativos". Es, más bien, que este tipo de discurso (del cual el de Prensky no es más que un ejemplo), al naturalizarse, los induce a adoptar unas creencias que los descalifican.

En realidad, como se ha visto en los ejemplos proporcionados en este trabajo, los estudiantes se dirigen a sus maestros por orientación acerca de lo que encuentran en la Red, porque como adultos formados los docentes son quienes están en mejores condiciones de contextualizar, cribar, aumentar o, mejor aún, ayudarlos a sintetizar la información.

El problema comunicacional no reside en que los alumnos sean "nativos" mientras que los profesores son "inmigrantes" digitales. La desinteligencia consiste en que los docentes se sienten tan disvaliosos que no se les ocurre pensar que los adolescentes no les están pidiendo que dominen las TIC mejor ni peor que ellos. Lo que les están solicitando es ayuda en la contextualización, interpretación, selección y ampliación de la hiperinfor- mación en la que muchos viven (no todos, y por este hecho también es objetable asignarles indiscriminadamente la categoría de "nativos").

\section{Conclusiones}

De los testimonios de los docentes de Misiones participantes en este estudio se desprende que tienen muy internalizada la creencia en su propia minusvalía en relación con el uso de las infotecnologías cuando se comparan con sus alumnos.

Por otra parte, la institución que en esta axiología debería contextualizar el aprendizaje - la escuela - se percibe reemplazada por el cibercafé. El modelo emisor/receptor no se considera falaz. Se estima normal, pero en vías de inversión. Es decir que el alumno sería crecientemente emisor, mientras que el docente sería crecientemente receptor. En estas circunstancias, como es predecible, el fin mismo de la educación - el aprendizajetiende a ser problematizado.

La aceptación de que los alumnos incorporen la computadora y la internet tanto para el juego como para ayudarlos en tareas escolares, depende mucho de cuál sea la percepción que tiene el docente acerca del valor actual del capital simbólico de su propio saber. El hecho de sentir que si no adquieren un mayor alfabetismo digital perderán capital simbólico hace que algunos docentes reaccionen incluso rechazando la tecnología. 
Los docentes traslucen inseguridad respecto a su autoridad y al control que pueden tener sobre los alumnos si estos manejan la tecnología de un modo que no pueden igualar.

Existe una percepción generalizada entre los profesores de no estar capacitados para su profesión porque hoy los alumnos "saben" más que ellos. En síntesis, hay ciertos obstáculos epistemológicos que, en la práctica, dificultan en el campo educativo la construcción de una "espiral del conocimiento" (Nonaka y Takeuchi 1995), donde los conocimientos tácitos y codificados de docentes y alumnos se potencien y realimenten entre sí. Ante esta percepción, algunos adoptan estrategias de resignación, otros intentan ponerse al día, y otros más tratan de prohibir ciertos usos de las TIC que perciben como "competencia". Todos quisieran imponer algún tipo de "economía moral" (Silverstone 1996).

Lo que no se ve es que intenten romper el modelo de pensamiento binario que los lleva a dividir a los actores de su campo entre quienes "saben" y quienes "no saben". Una división perfectamente análoga a la que, desde un lugar supuestamente analítico, hace Marc Prensky entre "nativos" e "inmigrantes" digitales.

Si quieren salir de este falso binarismo, los docentes no deberían tratar de mimetizarse con los presuntos "nativos" digitales. Más bien deberían pensar que para construir redes de co- nocimiento, como las descritas por Nonaka y Takeuchi, no es imprescindible confundirlas con redes sociales online. No tienen que perder de vista que - como adultos y profesionalesposeen herramientas de contextualización y análisis solo adquiribles con madurez y experiencia.

Difícilmente los adolescentes cuentan con esos mismos recursos para enfrentar aludes de información, que no necesariamente generan mayor conocimiento. Por lo tanto, este estudio pretende ser un aporte para facilitar la generación de políticas públicas orientadas a ayudar a los profesores a valorar, utilizar y reforzar las habilidades que sí tienen, como parte de un objetivo estratégico mayor de adaptar la escuela media al entorno cultural y tecnológico actual.

Para lograrlo, evidentemente, se debe abandonar la idea de que hay un "país" digital, con "inmigrantes" y "nativos". Un país realmente curioso porque, como en ningún otro, los nativos aprenden de los inmigrantes y gracias a los inventos realizados por estos. Además, en vez de estar de antemano en la sociedad de acogida, como sería lo lógico, estos extraños nativos llegaron después de los supuestos inmigrantes.

Por todo lo dicho, puede concluirse que la metáfora de Prensky es más descriptiva que explicativa, y que lo que pretende delinear es más mítico que fáctico. Entender a los más jóvenes siempre fue un desafío para los 
mayores. Que los jóvenes utilicen formas lingüísticas diferentes, tampoco es novedad. Que sus preferencias de consumo también difieran, es lo esperable. Se puede conjeturar que es por esto último que categorías como "nativos digitales" se hagan crecientemente subyugantes. Porque el consumo de los jóvenes es sumamente importante para fines de márketing. Y ensayos como el de Prensky podrían usarse para intentar decir, e incluso predecir, qué y cómo pueden las corporaciones venderles a los jóvenes.

Si como efecto secundario de la naturalización de ciertas metáforas un colectivo - como el de los docentes secundarios de Misiones (de bajos recursos, que trabajan en su mayoría en escuelas rurales y con telecentros más lejanos y costosos que en Buenos Aires) - se siente poco valioso, no es de esperar que a los adultos, dentro de esas empresas, les importe. Pensarán: "Dame pan y llámame inmigrante...".

\section{Bibliografía}

BECERRA SÁNCHEZ, Guadalupe (2003). "Maestros y computadoras: Percepciones y significados". Tesis doctoral. México: Universidad de Guadalajara, Coordinación General del Sistema para la Innovación del Aprendizaje (Innova).

Bennett, Sue; Maton, Karl y Lisa KerVIN (2008). "The 'digital natives' debate: A critical review of the eviden- ce". British Journal of Educational Technology. 5 de febrero. <http: //www.cheeps. com/karlmaton/pdf/ bjet.pdf>. [Consulta: 22 de noviembre del 2009.]

BOURDIEU, Pierre (1997). Espacio social y espacio simbólico. Razones prácticas. Barcelona: Anagrama.

Bourdieu, Pierre y Jean Claude PasseRON (1998). La reproducción: Elementos para una teoría del sistema de enseñanza. México: Fontamara.

Cabello, R.; Aprea, G.; Géliga Vargas, J.; González Gartland, G. y R. MOYANO (2006). Yo con la computadora no tengo nada que ver. Un estudio de las relaciones entre los maestros y las tecnologías informáticas en la enseñan$z a$. Buenos Aires: Prometeo Libros/ UNGS.

FERGUSON, Marjorie (1992). "The Mythology about Globalization". European Journal of Communication 7. Marzo.

FORD, Aníbal (2001). “Democracia, educación y acceso a la información". Conferencia dictada en la II Jornada Nacional de Bibliotecas Escolares, Biblioteca Nacional de Maestros. Buenos Aires, 21 de noviembre.

(1994). Navegaciones. Buenos Aires: Amorrortu.

FORD, Aníbal et al. (2005). Resto del mundo. Buenos Aires: Norma.

Jensen, K. B. y N. JANKOWSKI (eds.) (1993). Metodologías cualitativas de 
investigación en comunicación de masas. Barcelona: Bosch.

MAAS, Pablo (2009). "Inmigrantes y nativos digitales: Problemas de un estereotipo".Economedia. Clarín.com. Octubre. <http:// weblogs.clarin. com/economedia/2009/10/inmigrantes-y-nativos-digitales-los-problemas-de-un-estereotipo.html>. [Consulta: 22 de noviembre del 2009.]

Margaryan, Anoush y Alison LittleJOHN, (2008). "Are digital natives a myth or reality?: Students' use of technologies for learning". 11 de diciembre. <http://www.academy.gcal. ac.uk/anoush/documents/DigitalNativesMythOrReality-MargaryanAndLittlejohn-draft-111208.pdf >. [Consulta: 22 de noviembre del 2009.]

Martín-BArbero, Jesús (2000). "Culturas/Tecnicidades/Comunicación en Iberoamérica, unidad cultural en la diversidad". México: OEI. $<$ http://www.campus-oei.org/ cultu$\mathrm{ra} /$ barbero.htm $>$. [Consulta: 22 de noviembre del 2009].

MoscovicI, Serge (1986). De la ciencia al sentido común. Psicología social II. Barcelona: Paidós.

Murdock, G.; Hartman, P. y P. Gray (1996). “La contextualización del ordenador doméstico, recursos y prácticas", en Silverstone, Roger y E. Hirsch (eds.). Los efectos de la nueva comunicación. El consumo de la moderna tecnología en el hogar y la familia. Barcelona: Bosch.

NonaKa, I. y H. TAKeUChI (1995). The knowledge-creating company. Nueva York: Oxford University Press.

Prensky, M. (2004). "The death of command and control". Macprensky.com. Enero. <http:// www. marcprensky.com/writing/PrenskySNS-01-20-04.pdf>. [Consulta: 22 de noviembre de 2009].

(2001). “Digital Natives, Digital Inmigrants. On the Horizon". NCB University Press. Vol. 99, núm. 5.

Silverstone, Roger y E. Hirsch (eds.). (1996). Los efectos de la nueva comunicación. El consumo de la moderna tecnología en el hogar y la familia. Barcelona: Bosch.

SIRI, L. (2009). “La brecha digital, o cómo poner el carro delante del caballo". Alambre, Comunicación, Información, Cultura 2. Marzo. <http://www. revistaalambre.com/Articulos/ArticuloMuestra.asp?Id=31>. [Consulta: 22 de noviembre del 2009.] 